\title{
Manual Aspiration Thrombectomy Using Penumbra Catheter in Patients with Acute M2 Occlusion : A Single-Center Analysis
}

\author{
Jung Soo Park, M.D., ${ }^{1,2}$ Hyo Sung Kwak, M.D., \\ Departments of Neurosurgery, ${ }^{1}$ Radiology, ${ }^{3}$ and Research Institute of Clinical Medicine of Chonbuk National University-Biomedical Research Institute \\ of Chonbuk National University Hospital, ${ }^{2}$ Jeonju, Korea
}

Objective : The efficacy and safety of manual aspiration thrombectomy using Penumbra in an acute occlusion of large intracranial arteries has been proven in many previous studies. Our study aimed to retrospectively assess the efficacy and safety of manual aspiration thrombectomy using Penumbra in patients with small vessel occlusions (M2 segment of the MCA).

Methods : We conducted a retrospective review of 32 patients who underwent manual aspiration thrombectomy using the Penumbra 4 MAX Reperfusion Catheter for treatment of an M2 occlusion between January 2013 and November 2014. We evaluated immediate angiographic results and clinical outcomes through review of patient electronic medical records.

Results : There were slightly more men in this study ( $\mathrm{M}: \mathrm{F}=18: 14)$ and the median age was 72.5 (age range : 41-90). The rate of successful recanalization ( $\mathrm{TICl}$ grade $\geq 2 \mathrm{~b}$ ) was $84 \%$ (27/32). NIHSS at discharge and favorable clinical outcomes at 3 months were significantly improved than baseline. Median initial NIHSS score was 10 (range : 4-25) and was 4 (range : 0-14) at discharge. Favorable clinical outcomes (mRS score $\leq 2$ at 3 months) were seen in 25 out of 32 patients (78\%). There were no procedure-related symptomatic intracerebral hemorrhages. One patient expired after discharge due to a cardiac problem.

Conclusion : Manual aspiration thrombectomy might be safe and is capable of achieving a high rate of successful recanalization and favorable clinical outcomes in patients with distal cerebral vessel occlusion (M2).

Key Words : Stroke · Thrombectomy · Middle cerebral artery.

\section{INTRODUCTION}

The early recanalization of occluded vessels in acute ischemic stroke (AIS) has been shown to be associated with improved clinical outcomes and reduced mortality ${ }^{11)}$. Yet until 2004, the only FDA-approved treatment modality for AIS was an intravenous administration with tissue plasminogen activator (tPA). However, because tPA is associated with a low recanalization rate for large vessel occlusions, intraarterial endovascular therapy (EVT), with various mechanical devices such as a retriever stent or aspiration catheter, was developed and has resulted in better recanalization of these larger vessels ${ }^{4,7,12}$.

Recently, manual aspiration thrombectomy (MAT), using a new generation of easy-to-track large-bore aspiration catheters, as a first approach for AIS has been reported with favorable out- comes $^{5,6,16)}$. However, the benefit of aggressive EVT for occlusion of an isolated M2 segment of a middle cerebral artery (MCA) remains unclear. The purpose of this study was to describe safety, angiographic and clinical outcomes of MAT using Penumbra reperfusion catheter (Penumbra, Alameda, CA, USA) in patients with a solitary $\mathrm{M} 2$ occlusion in a single-center analysis.

\section{MATERIALS AND METHODS}

This retrospective study was approved by our institutional review board.

\section{Patient selection}

From January 2013 to November 2014, 32 patients with AIS secondary to a solitary M2 occlusion were treated with MAT us-

- Received : August 4, 2015 • Revised : March 2, 2016 • Accepted : March 4, 2016

- Address for reprints : Hyo Sung Kwak, M.D.

Department of Radiology and the Research Institute of Medical Science, Chonbuk National University Medical School and Hospital, 20 Geonij-ro, Deokjin-gu, Jeonju 54907 , Korea

Tel : +82-63-250-2582, Fax : +82-63-272-0481, E-mail : kwak8140@jbnu.ac.kr

- This is an Open Access article distributed under the terms of the Creative Commons Attribution Non-Commercial License (http://creativecommons.org/licenses/by-nc/3.0) which permits unrestricted non-commercial use, distribution, and reproduction in any medium, provided the original work is properly cited. 
ing a penumbra reperfusion catheter as a first-line EVT. All patients were initially evaluated using computed tomography (CT) or magnetic resonance (MR) imaging, and angiographic status of patients was assessed routinely on MR angiography or threedimensional CT angiography. Inclusion criteria for EVT were an initial National Institutes of Health Stroke Scale (NIHSS) $\geq 4$, no evidence of intracerebral hemorrhage, obvious major vessel occlusion on CT or MR angiography, infarct core volume less than one-third of the MCA territory, perfusion deficit more than twothird of the MCA territory or perfusion deficit volume on MR at least $30 \%$ larger than the lesion volume shown on diffusionweighted MR, and patients within 8 hours from onset of symptoms. A CT scan was routinely performed immediately after the procedure.

On admission, the NIHSS score was assessed by a stroke neurologist. Eligible patients who met standard National Institute of Neurologic Disorders and Stroke criteria were treated with $0.9 \mathrm{mg} / \mathrm{kg}$ of IV $\mathrm{rtPA}^{3)}$. Subsequent EVT was considered for patients with no neurological improvement within $1 \mathrm{~h}$ of IV rtPA, defined as an unchanged NIHSS score from baseline or a worsening neurological deficit.

\section{Recanalization procedure}

All procedures were performed under conscious sedation by the same interventional neuroradiologist with 10 years of experience. Written informed consent for the EVT was obtained from all patients or next of kin. After femoral artery puncture, a 100cm 8 Fr guide catheter (Guider Softip; Stryker, Natick, MA, USA) was advanced as distally as possible through a triple coaxial system, which was assembled by combining the outermost $80-\mathrm{cm}$ 8 Fr shuttle sheath (Shuttle-SL; Cook, Bloomington, ID, USA) and inner 125-cm selection catheter (Headhunter; Cook, Bloomington, ID, USA). Then, systemic anticoagulation was initiated with a 3000-U bolus of intravenous heparin followed by 1000 $\mathrm{U} / \mathrm{hr}$ infusion. After occlusion of the M2 branch was defined by angiography, a 4MAX Penumbra reperfusion catheter was advanced to the level of the thrombus triaxially over a Rebar 18 microcatheter (EV3, Irvine, CA, USA) and Synchro 0.014-inch guidewire (Stryker, Freemont, CA, USA) under roadmap guid- ance. At the level of the thrombus, the guidewire and microcatheter were advanced more distally through the thrombus up to the distal M2 segment of the MCA in order to achieve sufficient support to track the reperfusion catheter. Next, we gently advanced the Penumbra catheter and wedged it tightly against the thrombus. Subsequently, the microcatheter and wire were removed and a $20-\mathrm{mL}$ syringe was connected to the proximal hub of the reperfusion catheter. Continuous manual aspiration was performed, maintaining the vacuum state between the tip of catheter and the thrombus while gently withdrawing the Penumbra catheter through the guide catheter (Fig. 1).

\section{Outcome measures}

We retrospectively analyzed patient medical records to determine demographic, clinical and angiographic data. The degree of vessel occlusion after treatment was defined by the Thrombolysis in Cerebral Infarction (TICI) scale; successful recanalization after treatment was defined as TICI scale score $\geq 2 \mathrm{~b}$. The NIHSS and modified Rankin scale (mRS) were checked on ad-

Table 1. Baseline characteristics of 32 patients

\begin{tabular}{lc}
\hline \multicolumn{1}{c}{ Characteristics } & Patients $(\mathrm{n}=32)$ \\
\hline Age, years $($ mean \pm SD) & $70.1 \pm 10.8$ \\
Sex, male $[\mathrm{n},(\%)]$ & $18(52)$ \\
Risk factor $[\mathrm{n},(\%)]$ & \\
Hypertension & $16(50)$ \\
Atrial fibrillation & $3(9)$ \\
Diabetes mellitus & $4(13)$ \\
Dyslipidemia & $5(16)$ \\
Smoking & $6(19)$ \\
History of stroke or TIA & $5(16)$ \\
Other heart disease & $3(9)$ \\
Occlusion site & \\
Rt S & $12(37)$ \\
Rt I & $10(31)$ \\
Lt S & $5(16)$ \\
LT I & $5(16)$
\end{tabular}

TIA : transient ischemic attack, Rt : right, Lt : left, S : M2 superior division, I : M2 inferior division
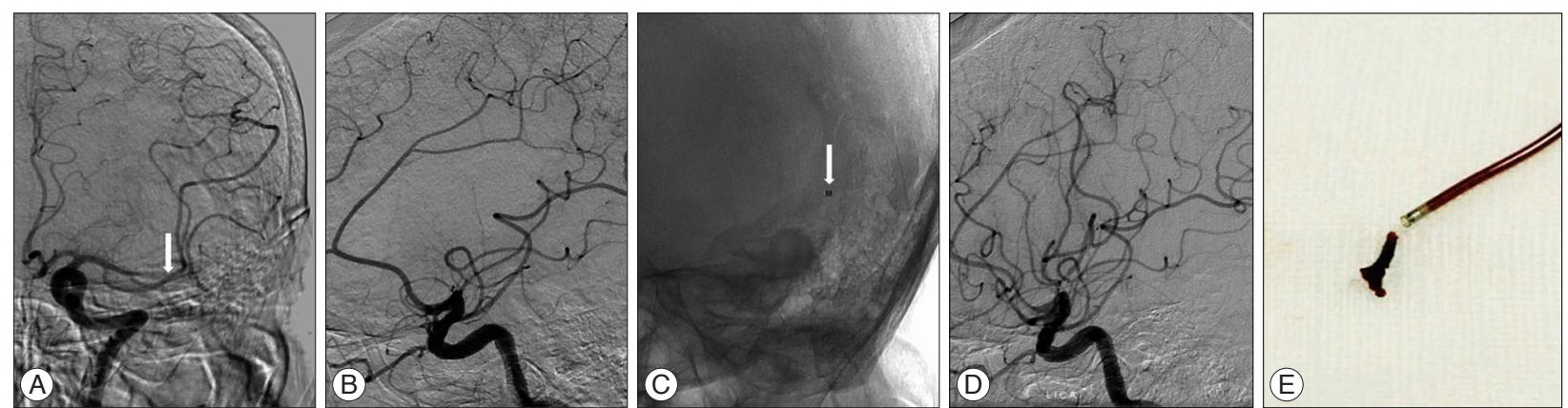

Fig. 1. Patient No. 27. Occlusion of the left $M 2$ superior division. $A$ : An initial anteroposterior angiogram shows occlusion of the proximal portion of the left M2 superior division (arrow). B : An initial lateral projection of angiography shows no visualization of M2 superior branch. C : Positioning of the Penumbra 4 MAX catheter in relation to the clot (arrow). D : An immediate post-procedural angiogram shows complete revascularization (TICI 3). E : Image of the clot retrieved by MAT. TICl : Thrombolysis in Cerebral Infarction, MAT : manual aspiration thrombectomy. 
mission and at 3 months for all patients and a favorable functional outcome was defined as a $\mathrm{mRS}$ score of $\leq 2$. Procedurerelated symptomatic intracerebral hemorrhage $(\mathrm{ICH})$ was defined as the presence of hemorrhage after treatment with any indication of increasing NIHSS compared to baseline on admission. Mortality was defined as death within 90 days from initial attack. Demographics and outcomes were analyzed using the paired ttest with PASW Statistics ver. 18.0 (SPSS Inc., Chicago, IL, USA). Statistically significant differences were defined as $p<0.05$.

\section{RESULTS}

From January 2013 to November 2014, one hundred twenty- two patients with AIS in the MCA territory were treated with MAT using a Penumbra reperfusion catheter as a first-line EVT. Of these patients, 32 with solitary M2 occlusions received MAS with Penumbra 4 Max.

Baseline, clinical and radiologic characteristics of 32 total subjects are shown in Table 1,2. The mean age of the patients was $70.1 \pm 10.8$ years (mean \pm standard deviation); $56 \%$ were men $(18 / 32)$. Sites of occlusion were as follows : right M2 superior division, 37\% (12/32); right M2 inferior division, 31\% (10/32); left M2 superior division, 16\% (5/32); left M2 inferior division, $16 \%(5 / 32)$. The mean interval from the onset of symptoms to groin puncture was $3.9 \pm 1.5$ hours, and mean procedure time was $33.2 \pm 12.6$ minutes. Final recanalization result of TICI $\geq 2 b$

Table 2. Clinical and radiologic characteristics of 32 patients

\begin{tabular}{|c|c|c|c|c|c|c|c|c|c|c|c|}
\hline No. & $\begin{array}{l}\text { Occluded } \\
\text { artery }\end{array}$ & $\begin{array}{l}\text { Baseline } \\
\text { NIHSS }\end{array}$ & $\begin{array}{l}\text { Discharge } \\
\text { NIHSS }\end{array}$ & $\begin{array}{l}\text { Final } \\
\text { TICI }\end{array}$ & $\begin{array}{l}\text { Onset to door } \\
\text { time (min) }\end{array}$ & $\begin{array}{l}\text { Onset to tPA } \\
\text { time (min) }\end{array}$ & $\begin{array}{l}\text { Onset to groin } \\
\text { puncture (min) }\end{array}$ & $\begin{array}{l}\text { Procedure } \\
\text { time (min) }\end{array}$ & $\begin{array}{c}\text { Baseline } \\
\text { mRS }\end{array}$ & $\begin{array}{l}\mathrm{mRS} \text { at } \\
90 \text { days }\end{array}$ & Complication \\
\hline 1 & Lt S & 5 & 1 & 3 & 120 & 140 & 163 & 20 & 4 & 0 & $\begin{array}{l}\text { Small ICH on } \\
\text { infarction core }\end{array}$ \\
\hline 2 & Rt $S$ & 13 & 9 & $2 \mathrm{a}$ & 42 & 90 & 157 & 25 & 4 & 6 & \\
\hline 3 & Rt $S$ & 10 & 9 & $2 b$ & 270 & N/A & 370 & 50 & 4 & 4 & \\
\hline 4 & Rt $S$ & 13 & 12 & $2 \mathrm{~b}$ & 120 & 175 & 240 & 23 & 4 & 4 & \\
\hline 5 & Rt S & 8 & 3 & $2 b$ & 65 & 90 & 155 & 25 & 3 & 2 & \\
\hline 6 & Lt I & 8 & 0 & 3 & 60 & 150 & 240 & 35 & 4 & 0 & \\
\hline 7 & Rt I & 8 & 2 & 3 & 60 & 100 & 180 & 20 & 3 & 1 & $\begin{array}{l}\text { Small ICH on } \\
\text { infarction core }\end{array}$ \\
\hline 8 & Lt I & 25 & 20 & 3 & 30 & 150 & 280 & 20 & 5 & 4 & \\
\hline 9 & Rt $S$ & 15 & 0 & 0 & 40 & 80 & 140 & 30 & 5 & 1 & \\
\hline 10 & Rt I & 18 & 6 & $2 \mathrm{~b}$ & 280 & N/A & 400 & 30 & 5 & 1 & \\
\hline 11 & Lt $S$ & 4 & 0 & $2 b$ & 300 & N/A & 400 & 60 & 3 & 0 & \\
\hline 12 & Lt I & 10 & 2 & $2 \mathrm{~b}$ & 100 & 150 & 220 & 40 & 4 & 0 & \\
\hline 13 & Rt I & 7 & 0 & $2 a$ & 100 & 130 & 200 & 50 & 2 & 0 & \\
\hline 14 & Rt I & 12 & 0 & 3 & 30 & 40 & 90 & 30 & 4 & 0 & \\
\hline 15 & Rt I & 22 & 8 & 0 & 280 & N/A & 360 & 20 & 4 & 2 & \\
\hline 16 & Rt I & 10 & 6 & 3 & 120 & 160 & 270 & 20 & 3 & 1 & \\
\hline 17 & Rt S & 7 & 4 & $2 \mathrm{~b}$ & 60 & 90 & 150 & 45 & 3 & 1 & \\
\hline 18 & Lt S & 11 & 10 & 3 & 60 & 150 & 240 & 60 & 3 & 3 & \\
\hline 19 & Rt I & 8 & 3 & $2 b$ & 30 & 70 & 150 & 30 & 3 & 1 & \\
\hline 20 & Lt I & 16 & 11 & $2 b$ & 70 & 100 & 190 & 40 & 4 & 1 & \\
\hline 21 & Lt I & 18 & 4 & $2 b$ & 60 & 95 & 210 & 30 & 4 & 1 & $\begin{array}{l}\text { Small ICH on } \\
\text { infarction core }\end{array}$ \\
\hline 22 & LT S & 14 & 4 & 3 & 60 & 80 & 180 & 30 & 4 & 0 & \\
\hline 23 & Rt S & 6 & 3 & 3 & 120 & 160 & 280 & 40 & 3 & 1 & \\
\hline 24 & Rt S & 5 & 4 & $2 b$ & 60 & 85 & 120 & 30 & 3 & 1 & \\
\hline 25 & Rt S & 11 & 5 & $2 \mathrm{a}$ & 120 & 150 & 240 & 40 & 4 & 3 & \\
\hline 26 & Rt I & 4 & 0 & $2 \mathrm{~b}$ & 160 & 195 & 280 & 60 & 3 & 0 & \\
\hline 27 & Rt S & 12 & 4 & 3 & 40 & 90 & 140 & 35 & 1 & 1 & \\
\hline 28 & Rt S & 7 & 6 & 3 & 35 & 65 & 390 & 20 & 4 & 2 & \\
\hline 39 & Rt I & 5 & 1 & 3 & 75 & 150 & 360 & 40 & 2 & 0 & \\
\hline 30 & Rt I & 10 & 4 & 3 & 135 & 190 & 370 & 15 & 2 & 1 & \\
\hline 31 & Lt S & 17 & 14 & 3 & 20 & 80 & 140 & 30 & 4 & 4 & \\
\hline 32 & Rt S & 10 & 7 & 3 & 30 & 100 & 197 & 20 & 4 & 2 & \\
\hline
\end{tabular}

NIHSS : National Institute of Health Stroke Scale, TICl : Thrombolysis in Cerebral Infarction, tPA : tissue plasminogen activator, mRS : modified Rankin scale, ICH : intracerebral hemorrhage, N/A : not applicable, S : M2 superior division, I : M2 inferior division 
was achieved in 84\% (27/32), and TICI 3 in 47\% (15/32) of patients. Baseline NIHSS score was $10.9 \pm 5.1$, and improved to $4.3 \pm 4.0$ by the time of discharge. Favorable functional outcomes (mRS score $\leq 2$ at 3 months) resulted in 25 out of 32 (78\%) patients, with one death occurring after discharge (Table 3 ). There were three cases of procedure-related small $\mathrm{ICH}$, but without neurologic deterioration.

\section{DISCUSSION}

Infarction of the MCA territory accounts for the largest proportion of AIS populations. Depending on the specific MCA occlusion site, initial presentations and clinical outcomes can manifest very differently. The patients with a MCA main trunk (M1) infarction demonstrated a severe neurological deficit and had poor functional outcomes similar to occlusions in the internal carotid artery $(\mathrm{ICA})^{14)}$. Thus, early recanalization of M1 occlusion is crucial in order to achieve good functional outcomes, regardless of treatment modality. Comparatively, isolated M2 segment infarctions tend to display relatively mild neurological symptoms compared to M1 occlusions. This is because the M2 division usually separates into at least two branches and involves a more limited vascular territory ${ }^{9,10)}$. For this reason, the benefit

Table 3. Demographics and outcomes of MAT in patients with solitary M2 occlusion

\begin{tabular}{|c|c|c|}
\hline Outcome parameter & & $p$ value $^{*}$ \\
\hline \multicolumn{3}{|l|}{ Final TICI [n (\%)] } \\
\hline $0-2 \mathrm{a}$ & $5(16)$ & \\
\hline $2 \mathrm{~b}$ & $12(37)$ & \\
\hline 3 & $15(47)$ & \\
\hline NIHSS (mean \pm SD) & & $<0.0001$ \\
\hline Baseline & $10.9 \pm 5.1$ & \\
\hline Discharge & $4.3 \pm 4.0$ & \\
\hline $\mathrm{mRS} \leq 2[\mathrm{n}(\%)]$ & & $<0.0001$ \\
\hline Baseline & $4(13)$ & \\
\hline At 90 days & $25(78)$ & \\
\hline
\end{tabular}

of aggressive EVT for M2 occlusions remains a controversial issue. However, the prognosis of AIS due to M2 occlusions is not always favorable, and a small, yet strategic cerebral infarction may still lead to permanent disabilities. Sheth et al. ${ }^{13)}$ reported that half of patients with M2 occlusions were discharged with moderately severe disability or death; a rate comparable to that of patients with $\mathrm{M} 1$ occlusions. Also, Wolpert et al. ${ }^{17)}$ reported an insufficient efficacy of IV tPA for M2 occlusions; a recanalization rate of only $30 \%$. Given these facts, solitary M2 occlusions should be considered as potential targets for EVT.

Despite this, previous studies have reported conflicting results about the efficacy of early recanalization of M2 occlusions ${ }^{1,10,15)}$. Broderick et al. ${ }^{1)}$ reported similar safety outcomes and no significant differences in functional independence with EVT after IV tPA, as compared with IV tPA alone. Rahme et al. ${ }^{10)}$ and Tomsick et al. ${ }^{15)}$ concluded that a positive correlation between successful early reperfusion and a favorable outcome could not be applied to patients with M2 occlusions. Yet, more recently, some other studies presenting a positive correlation between early recanalization via EVT and favorable outcomes in patients with M2 occlusions have been reported ${ }^{2,9,13,14)}$. Although reported recanalization rates and favorable functional outcomes in the literature have a variable range, these results overall showed comparative or favorable outcomes compared with traditional IV tPA treatment (Table 4). In particular, our work using a penumbra 4 MAX catheter showed a higher recanalization rate compared with other solitary M2 occlusion case series. We felt it was very important that the reperfusion catheter tip be brought into close contact with the thrombus in order to increase the recanalization rate. Thus, the authors advanced a relatively large-bore $8 \mathrm{Fr}$ shuttle sheath and guiding catheter as distally as possible for proximal support, and used a 153-cm long Rebar 18 microcatheter (EV3, Irvine, CA, USA), which is more than $3 \mathrm{~cm}$ longer compared with other commercial microcatheters, to achieve sufficient distal support. Through these technical measures, we could easily track and advance the Penumbra catheter into the thrombus during procedures and consequently, obtain higher recanalization rates and favorable outcomes.

Currently, the main instruments of EVT for AIS are stent-re-

Table 4. Studies showing favorable outcomes of EVT for patients with solitary M2 occlusions

\begin{tabular}{|c|c|c|c|c|c|}
\hline Authors & $\begin{array}{c}\text { Case } \\
\text { numbers (n) }\end{array}$ & $\begin{array}{c}\text { Successful } \\
\text { recanalization rate (\%) }\end{array}$ & $\begin{array}{c}\text { Favorable clinical } \\
\text { outcome }(\%)\end{array}$ & EVT modalities & Comment \\
\hline Shi et al. $(2010)^{14)}$ & 28 & 82.1 & 40.7 & Stent retriever & $\begin{array}{l}\text { Subgroup analysis of the } \\
\text { MERCI trial }\end{array}$ \\
\hline Rahme et al. $(2013)^{9)}$ & 30 & 50 & 53.3 & IA r-proUK & $\begin{array}{l}\text { Subgroup analysis of the } \\
\text { PROACT II trial }\end{array}$ \\
\hline Sheth et al. $(2014)^{13)}$ & 52 & 44 & 55.3 & $\begin{array}{l}\text { IA tPA, MERCI, angioplasty, } \\
\text { Solitaire, mechanical } \\
\text { disruption }\end{array}$ & $\begin{array}{l}\text { Single-center using } \\
\text { Multimodal techniques }\end{array}$ \\
\hline Flores et al. $(2015)^{2)}$ & 65 & 78.5 & 60 & IA tPA, stent retriever & Multicenter analysis \\
\hline Present series & 32 & 84 & 78 & $\begin{array}{l}\text { Manual aspiration } \\
\text { thrombectomy (MAT) }\end{array}$ & $\begin{array}{l}\text { Single-center analysis using } \\
\text { MAT only }\end{array}$ \\
\hline
\end{tabular}


trievers that displayed device efficacy and favorable clinical outcomes in several comparative randomized trials ${ }^{7,8,12)}$. However, most of the patients in those trials were diagnosed with AIS due to large vessel occlusion, so the efficacy and favorable outcomes of stent-retrievers are not applicable to solitary occlusions in relatively smaller vessels, such as the MCA-M2. Indeed, M2 divisions of the MCA are more distal vessels with a smaller caliber and thinner walls compared with the ICA or M1 trunk, rendering them more vulnerable to possible vessel wall damage during retraction of the deployed stent ${ }^{2,10}$.

Recently, several reports have described a manual aspiration technique known as MAT, forced-suction thrombectomy, or the ADAPT technique with promising results regarding recanalization rate, cost effectiveness, procedure duration and functional outcomes ${ }^{5,6,16)}$. These techniques are generally carried out using the newest generation of flexible and large-bore catheters. In our study, we applied MAT for solitary M2 occlusions with the Penumbra 4 MAX catheter. Our preliminary results indicate that this technique is feasible as a first-line therapy for relatively thin and small M2 lesions. In addition, the evolution of devices, such as more supportive microcatheters and more flexible catheters, is expected to provide an expanding scope of application for the manual aspiration technique in EVT for AIS.

To our knowledge, this report is the first single-center case analysis describing the safety and favorable outcomes of MAT using large-bore and flexible catheters for solitary M2 occlusions. However, our study has several limitations. First, it lacks a prospective design; second, our study is a relatively small case series; third, we lack a control group, such as patients treated with other EVT modalities or medical therapy.

\section{CONCLUSION}

In our experience, MAT using the Penumbra 4 MAX catheter can achieve good angiographic and functional outcomes without serious complications in patients with solitary M2 occlusions. Further well-designed prospective randomized studies should provide definitive evidence regarding this approach compared with other treatment modalities in M2 occlusion.

\section{- Acknowledgements}

This paper was supported by research funds from Chonbuk National University in 2014.

\section{References}

1. Broderick JP, Palesch YY, Demchuk AM, Yeatts SD, Khatri P, Hill MD, et al. : Endovascular therapy after intravenous t-PA versus t-PA alone for stroke. N Engl J Med 368 : 893-903, 2013

2. Flores A, Tomasello A, Cardona P, de Miquel MA, Gomis M, Garcia
Bermejo P, et al. : Endovascular treatment for M2 occlusions in the era of stentrievers : a descriptive multicenter experience. J Neurointerv Surg $7: 234-237,2015$

3. Hacke W, Kaste M, Bluhmki E, Brozman M, Dávalos A, Guidetti D, et al. : Thrombolysis with alteplase 3 to 4.5 hours after acute ischemic stroke. N Engl J Med 359 : 1317-1329, 2008

4. IMS II Trial Investigators : The Interventional Management of Stroke (IMS) II Study. Stroke $38: 2127-2135,2007$

5. Jankowitz B, Aghaebrahim A, Zirra A, Spataru O, Zaidi S, Jumaa M, et al. : Manual aspiration thrombectomy : adjunctive endovascular recanalization technique in acute stroke interventions. Stroke 43 : 1408-1411, 2012

6. Kang DH, Hwang YH, Kim YS, Park J, Kwon O, Jung C : Direct thrombus retrieval using the reperfusion catheter of the penumbra system : forced-suction thrombectomy in acute ischemic stroke. AJNR Am J Neuroradiol $32: 283-287,2011$

7. Nogueira RG, Lutsep HL, Gupta R, Jovin TG, Albers GW, Walker GA, et al. : Trevo versus Merci retrievers for thrombectomy revascularisation of large vessel occlusions in acute ischaemic stroke (TREVO 2) : a randomised trial. Lancet 380 : 1231-1240, 2012

8. Pereira VM, Gralla J, Davalos A, Bonafé A, Castaño C, Chapot R, et al. : Prospective, multicenter, single-arm study of mechanical thrombectomy using Solitaire Flow Restoration in acute ischemic stroke. Stroke 44 : 2802-2807, 2013

9. Rahme R, Abruzzo TA, Martin RH, Tomsick TA, Ringer AJ, Furlan AJ, et al. : Is intra-arterial thrombolysis beneficial for M2 occlusions? Subgroup analysis of the PROACT-II trial. Stroke 44 : 240-242, 2013

10. Rahme R, Yeatts SD, Abruzzo TA, Jimenez L, Fan L, Tomsick TA, et al. : Early reperfusion and clinical outcomes in patients with M2 occlusion : pooled analysis of the PROACT II, IMS, and IMS II studies. J Neurosurg 121 : 1354-1358, 2014

11. Rha JH, Saver JL: The impact of recanalization on ischemic stroke outcome : a meta-analysis. Stroke 38 : 967-973, 2007

12. Saver JL, Jahan R, Levy EI, Jovin TG, Baxter B, Nogueira RG, et al. : Solitaire flow restoration device versus the Merci Retriever in patients with acute ischaemic stroke (SWIFT) : a randomised, parallel-group, non-inferiority trial. Lancet $380: 1241-1249,2012$

13. Sheth SA, Yoo B, Saver JL, Starkman S, Ali LK, Kim D, et al. : M2 occlusions as targets for endovascular therapy : comprehensive analysis of diffusion/perfusion MRI, angiography, and clinical outcomes. J Neurointerv Surg $7: 478-483,2015$

14. Shi ZS, Loh Y, Walker G, Duckwiler GR; MERCI and Multi-MERCI Investigators : Clinical outcomes in middle cerebral artery trunk occlusions versus secondary division occlusions after mechanical thrombectomy : pooled analysis of the Mechanical Embolus Removal in Cerebral Ischemia (MERCI) and Multi MERCI trials. Stroke 41 : 953-960, 2010

15. Tomsick T, Broderick J, Carrozella J, Khatri P, Hill M, Palesch Y, et al. : Revascularization results in the Interventional Management of Stroke II trial. AJNR Am J Neuroradiol 29 : 582-587, 2008

16. Turk AS, Spiotta A, Frei D, Mocco J, Baxter B, Fiorella D, et al. : Initial clinical experience with the ADAPT technique : a direct aspiration first pass technique for stroke thrombectomy. J Neurointerv Surg 6 : 231-237, 2014

17. Wolpert SM, Bruckmann H, Greenlee R, Wechsler L, Pessin MS, del Zoppo GJ : Neuroradiologic evaluation of patients with acute stroke treated with recombinant tissue plasminogen activator. The rt-PA Acute Stroke Study Group. AJNR Am J Neuroradiol 14 : 3-13, 1993 